\title{
A Bacterial Parasite Effector Mediates Insect Vector Attraction in Host Plants Independently of Developmental Changes
}

\author{
Zigmunds Orlovskis and Saskia A. Hogenhout* \\ Department of Cell and Developmental Biology, John Innes Centre, Norwich Research Park, Norwich, UK
}

Parasites can take over their hosts and trigger dramatic changes in host appearance and behavior that are typically interpreted as extended phenotypes that promote parasite survival and fitness. For example, Toxoplasma gondii is thought to manipulate the behaviors of infected rodents to aid transmission to cats and parasitic trematodes of the genus Ribeiroia alter limb development in their amphibian hosts to facilitate predation of the latter by birds. Plant parasites and pathogens also reprogram host development and morphology. However, whereas some parasite-induced morphological alterations may have a direct benefit to the fitness of the parasite and may therefore be adaptive, other

OPEN ACCESS

Edited by: Carolina Escobar, Universidad de Castilla La Mancha,

Spain

Reviewed by:

Biswapriya Biswavas Misra, University of Florida, USA Ben Petre,

The Sainsbury Laboratory, UK

${ }^{*}$ Correspondence:

Saskia A. Hogenhout

saskia.hogenhout@jic.ac.uk

Specialty section: This article was submitted to Plant Biotic Interactions, a section of the journal Frontiers in Plant Science

Received: 15 March 2016 Accepted: 06 June 2016

Published: 23 June 2016

Citation:

Orlovskis $Z$ and Hogenhout SA (2016) A Bacterial Parasite Effector

Mediates Insect Vector Attraction in Host Plants Independently of Developmental Changes.

Front. Plant Sci. 7:885.

doi: 10.3389/fpls.2016.00885 host alterations may be side effects of parasite infections having no adaptive effects on parasite fitness. Phytoplasma parasites of plants often induce the development of leaf-like flowers (phyllody) in their host plants, and we previously found that the phytoplasma effector SAP54 generates these leaf-like flowers via the degradation of plant MADS-box transcription factors (MTFs), which regulate all major aspects of development in plants. Leafhoppers prefer to reproduce on phytoplasma-infected and SAP54-trangenic plants leading to the hypothesis that leafhopper vectors are attracted to plants with leaf-like flowers. Surprisingly, here we show that leafhopper attraction occurs independently of the presence of leaf-like flowers. First, the leafhoppers were also attracted to SAP54 transgenic plants without leaf-like flowers and to single leaves of these plants. Moreover, leafhoppers were not attracted to leaf-like flowers of MTFmutant plants without the presence of SAP54. Thus, the primary role of SAP54 is to attract leafhopper vectors, which spread the phytoplasmas, and the generation of leaflike flowers may be secondary or a side effect of the SAP54-mediated degradation of MTFs.

Keywords: plant-microbe-insect interactions, effector biology, floral development, parasite-host interactions, adaptation, host manipulation, insect behavior

\section{INTRODUCTION}

Parasite-induced changes of host bodies, including changes in host development and behavior, are viewed as extended phenotypes of parasite genes (Dawkins, 1982). The parasite genes modulate the host phenotype in a direction that will aid the propagation and spread of the parasite, but that can prove detrimental to the host (Dawkins, 1982, 1990). In some cases, parasite reprogramming 
of the host can lead to extreme changes in host development and behavior. For example, the severe limb malformations of frogs by trematodes of the genus Ribeiroia is thought to increase predation of the locomotion-impaired frogs by birds, which are essential for spread of the trematodes in the environment (Johnson et al., 2004). As well, rodents infected with Toxoplasma gondii change their behavior increasing the likelihood of predation by cats, which are the definitive hosts for T. gondii (Berdoy et al., 2000). However, mechanisms involved in parasite-mediated alterations of host phenotypes are mostly unknown limiting our ability to investigate if the modulations are adaptive (Poulin, 1995, 2013). Only a few parasite genes that orchestrate dramatic changes in host phenotype and behavior have been identified so far (Hoover et al., 2011; MacLean et al., 2011, 2014; Sugio et al., 2011a, 2014).

It is often unclear whether dramatic changes in host phenotype are adaptive or side effects (Dawkins, 1990, 2004; Poulin, 1995, 2013). Parasite genes cooperate with each other and interact with host genes generating variation in the extended phenotype depending on the combination of parasite/host genotypes (Dawkins, 1990). In addition, parasite genes may interfere with multiple host factors, some of which have multiple functions, therefore generating phenotypic side effects (Cezilly et al., 2013). For example, genes involved in plant or animal immune responses may also have roles in development and behavior; Toll-like receptors in Drosophila control development of body axis and defense responses to pathogenic fungi and bacteria (Lemaitre et al., 1996; Artero et al., 2003). Similarly, in plants, TEOSINTE BRANCHED1, CYCLOIDEA, PROLIFERATING CELL FACTORS 1 and 2 (TCP) and MADSbox transcription factors (MTFs) regulate major aspects of plant growth and organ development, but also regulate, for example, synthesis and downstream signaling of the plant hormones jasmonic acid (JA; Schommer et al., 2008; Immink et al., 2012) and salicylic acid (SA; Wang et al., 2015) that have roles in plant defense.

Phytoplasmas are phloem-limited parasitic bacteria that induce dramatic changes in the development of their plant hosts, including proliferation of stems (witch's brooms), conversion of flowers into leaf-like structures (phyllody) and stunting and yellowing (Bertaccini, 2007). Phytoplasmas depend on sapfeeding hemipteran insect vectors for transmission (Weintraub and Beanland, 2006). For Aster Yellows strain Witches' Broom (AY-WB) phytoplasma ('Candidatus' Phytoplasma asteris) it was found that infected plants are more attractive to the aster leafhopper Macrosteles quadrilineatus, which is the most important insect vector of AY-WB (Frost et al., 2011, 2013; Sugio et al., 2011a,b). The two AY-WB virulence proteins (effectors) SAP11 and SAP54 modulate Arabidopsis thaliana development and promote attraction and reproduction of insect vectors to phytoplasma-infected $A$. thaliana plants (MacLean et al., 2011, 2014; Sugio et al., 2011a,b). Effector SAP54 induces the production of green and indeterminate leaf-like flowers that resemble phyllody symptoms (MacLean et al., 2011). SAP54 acts by degrading specific MTFs via the $26 \mathrm{~S}$ proteasome requiring SAP54 interaction with the 26 S proteasome shuttle factor RAD23 (MacLean et al., 2014). Phyllody symptoms have been observed in a broad range of phytoplasma-infected crops and wild plant species and genes that have sequence similarities to AY-WB SAP54 are found in diverse phyllody-inducing phytoplasmas worldwide, suggesting that SAP54 effectors may have important contributions to phytoplasma fitness (MacLean et al., 2011; Maejima et al., 2014).

Leafhoppers feed and lay eggs mostly on green vegetation, which is more abundant in leaf-like flowers than in normal flowers (MacLean et al., 2011). Moreover, A. thaliana RAD23 is required for the SAP54 mediated development of leaf-like flowers and also for leafhopper preference (MacLean et al., 2014). Therefore, we hypothesized that the formation of leaflike flowers is a phytoplasma-induced extended phenotype to attract leafhopper vectors. Surprisingly, we found that the leaflike flowers do not play a role in insect vector preference. We argue that parasite-induced phenotypes of hosts are not always adaptive, even if the developmental changes induced by parasite infections are obvious (leaf-like flowers) and there is evidence of a mechanistic link (dependence on RAD23) between the developmental change of the host (leaf-like flowers) and factors that directly impact parasite fitness (attraction of insect vectors that spread phytoplasmas).

\section{MATERIALS AND METHODS}

\section{Rearing of Insects}

Phytoplasma-free colonies of Macrosteles quadrilineatus Forbes (Hemiptera: Cicadellidae) were maintained on pathogen-free oat plants (Avena sativa) in an aerated $50 \times 50 \times 50 \mathrm{~cm}$ transparent plastic cage at $22^{\circ} \mathrm{C}$, long day photoperiod (16/8-h light/dark), $48 \%$ humidity. Phytoplasma-infected colonies were reared on AY-WB-infected China aster (Callistephus chinensis) and lettuce (Lactuca sativa) under the same conditions as healthy insect colonies.

\section{Generation of Plants for Leafhopper Choice Assays}

Generation of 35S:GFP-SAP54 and 35S:GFP transgenic Arabidopsis lines was done according to methods described in (MacLean et al., 2011). A. thaliana ap1 and lfy mutant were obtained from NASC (ID: N6232, allele ap1-12; ID: N6228, allele lfy-1). The 35S:SVP lines were kindly provided by Martin Kater and described in Gregis et al. (2013). The rad23 mutant lines were provided by Richard Vierstra and described in Vierstra (2009).

Non-flowering plants for insect choice experiments were sown on insecticide-free F2 compost soil (Levington, UK) and grown at $22^{\circ} \mathrm{C}$, short day photoperiod (10/14-h light/dark) for 8 weeks. In contract, flowering plants were grown at $22^{\circ} \mathrm{C}$, long day photoperiod (16/8-h light/dark) for 6 weeks. One week after germination transgenic lines 35S:GFP-SAP54 and 35S:GFP were sprayed twice (one-week interval) with herbicide Harvest $^{\circledR} \quad(13.52 \% \quad$ w/v glufosinate-amonium $)$ following manufacturers recommendations (Bayer, Cambridge, UK). Four-weeks old plants were transplanted into $10 \times 10 \times 10 \mathrm{~cm}$ $(H \times W \times D)$ plastic pots. Experiments involving pre-cut 


\section{A}

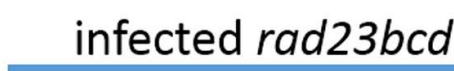

infected rad23bd
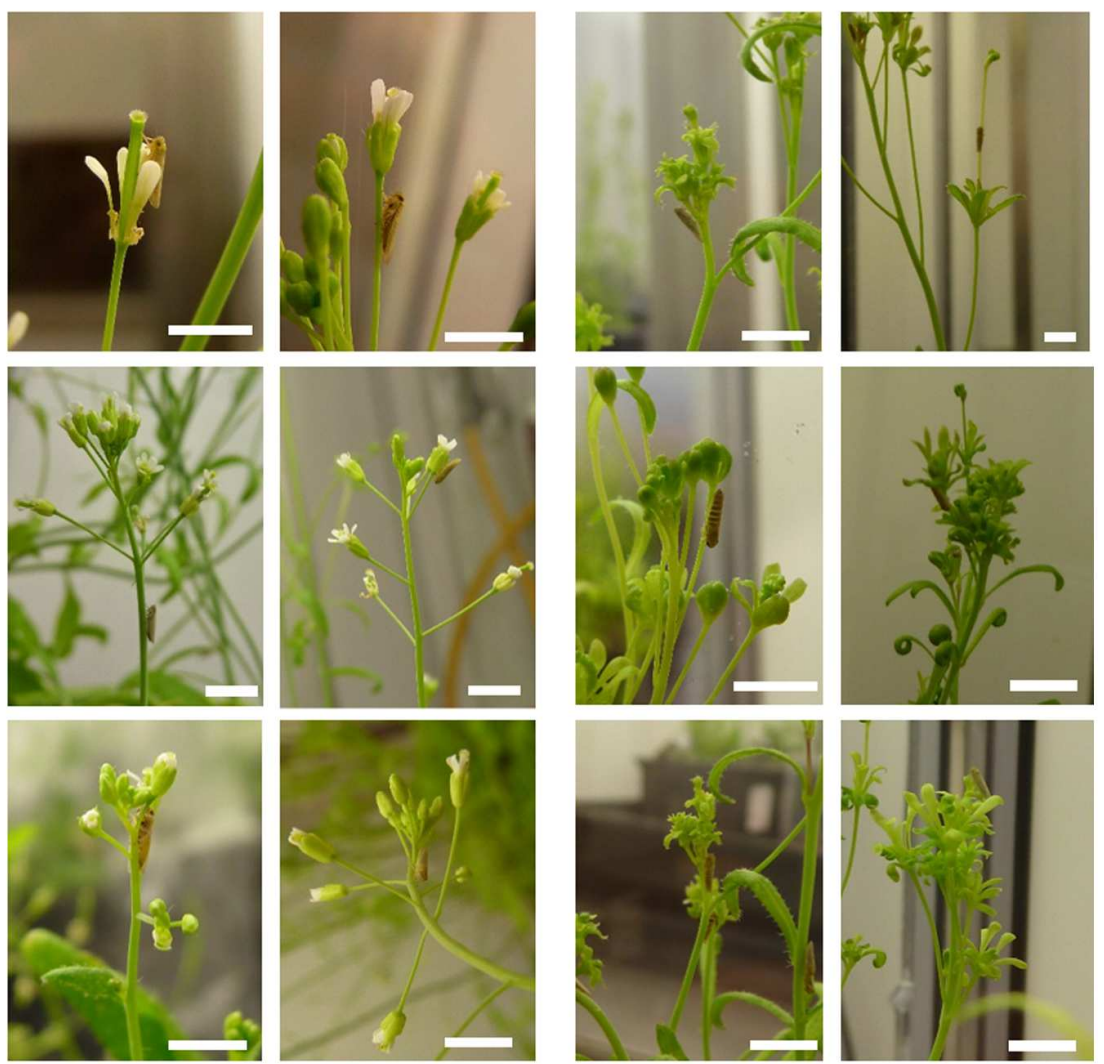

B

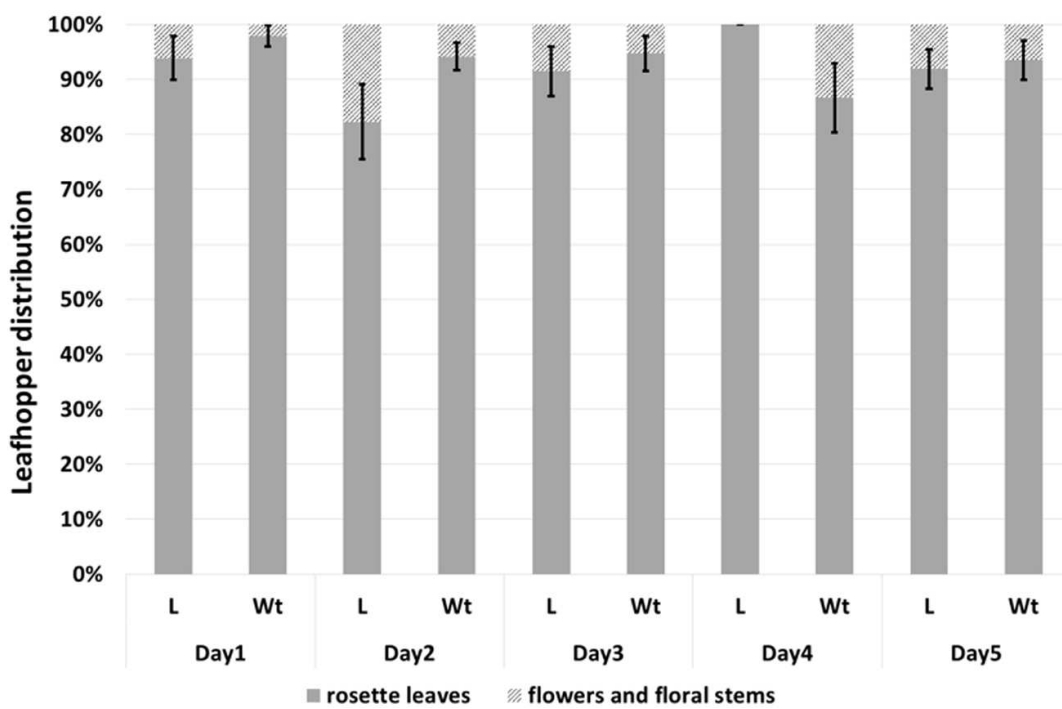

FIGURE 1 | Leafhoppers prefer vegetative plant tissues to flowers and have similar distribution on leaf-like and wild-type flowers. (A) Macrosteles quadrilineatus leafhoppers were photographed whilst residing and feeding on all parts of infected Arabidopsis thaliana rad23BD and rad23BCD plants, including rosette leaves and petioles, stems, cauline leaves and flowers. Insects were found on carpels, sepals, petals and pedicels of wild-type-looking $A$. thaliana flowers as well as leaf-like flowers. White scale bars on each picture are $1 \mathrm{~cm}$. (B) Number of insects found on rosettes or floral tissue is plotted as percentage of the total number of insects on wild-type plants and plants with leaf-like floral phenotype. Bars represent standard error of the mean of 8 independent replicate cages. M. quadrilineatus has significant residency preference for rosette leaves compared to other floral structures both on AY-WB infected rad23BCD mutant plants with leaf-like (L) flowers and AY-WB infected rad23BD mutant plants with wild-type flowers (GLM with time as covariate; $\left.F_{1,137}=1797.78 ; P \leq 0.001\right)$. There is no difference between insect residency on wild-type and leaf-like flowers during the five-day leafhopper choice experiment $\left(G L M\right.$ with time as covariate; $F_{1,67}=0.19$; $P=0.666)$. 


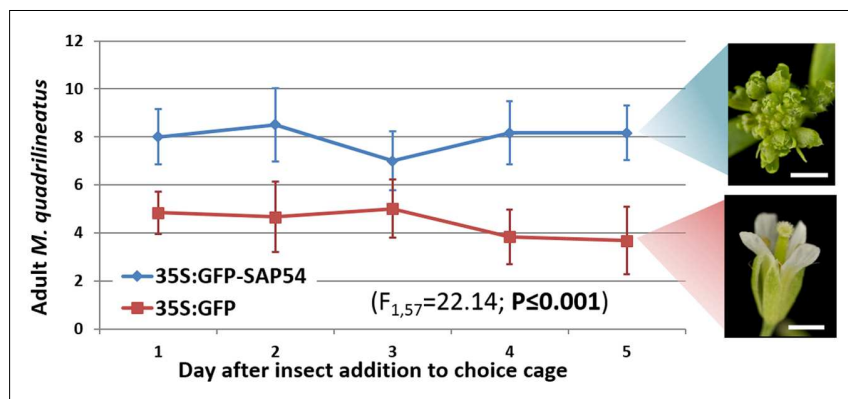

FIGURE 2 | Aster leafhopper M. quadrilineatus demonstrates greater residency preference for SAP54 expressing plants with leaf-like

flowers. More insects were found on SAP54 plants over the entire 5 day choice period (GLM with time as covariate; $F_{1,57}=22.14 ; P \leq 0.001$ ). Picture scale bar is $1 \mathrm{~mm}$. Bars in the graph are one standard error of the mean.

flowers, floral stems were removed by metal scissors 4 days prior to insect addition.

To generate infected plants (Figure 1), three-weeks old plants were infected with ' $C a$. Phytoplasma asteris' strain AY-WB by adding five AY-WB-carrying adult $M$. quadrilineatus to each plant in a transparent perspex tube $(10 \mathrm{~cm}$ high, diameter $4 \mathrm{~cm}$ ) for 5 days. Two weeks after the removal of adult insects, three rosette leaves were collected for extraction of genomic DNA to confirm phytoplasma infection using AY-WB specific primers BF $5^{\prime}$ AGGATGGAACCCTTCAATGTC $3^{\prime}$ and BR $5^{\prime}$ GGAAGTCGCCTACAAAAATCC 3’ (MacLean et al., 2014).

\section{Insect Choice Assays}

All insect choice experiments (Figures 1-3 and 5) were performed in transparent polycarbonate cages $62 \mathrm{~cm} \times 30 \mathrm{~cm} \times 41 \mathrm{~cm}(H \times W \times D)$. The opposite sides of the cage were fitted with white nylon mesh held by magnetic strips to the carcas of the cage for ventilation and access. GFP-SAP54 and GFP transgenic plants were placed randomly diagonally opposite each other in the corners of a cage. Ten male and ten female adult $M$. quadrilineatus, which did not carry AY-WB phytoplasma, were released from a transparent perspex tube $(9 \mathrm{~cm}$ high, diameter $3 \mathrm{~cm}$ ) in the center of the cage, at equal distance from each test plant. Adult insects were removed 5 days after addition to the cage. Plants were removed from the choice cage and contained individually in transparent perforated plastic bags at $22^{\circ} \mathrm{C}$, long day photoperiod (16/8-h light/dark). Nymphs were counted on each test plant 14 days after removal of adult insects from the cages. Data were expressed as proportion of total number of nymphs found on the test plants within each choice cage. Similar experiments were done with phytoplasma-infected and healthy plants or wild type and MTF-mutants plants.

\section{Insect No-Choice Assay}

For the no-choice experiment (Figure 4) five female and five male non-infected adult $M$. quadrilineatus were added to individual plants surrounded by a transparent plastic cage. Plants were grown and insect progeny measured as in choice experiments.

\section{Single-Leaf Insect Choice Assays}

For the experiment in Figure 3D, single rosette leaves that remained attached to GFP and GFP-SAP54 transgenic plants were fitted opposite each other in a $2 \mathrm{~cm} \times 8 \mathrm{~cm} \times 12 \mathrm{~cm}$ $(H \times W \times D)$ transparent plastic cage fitted with nylon meshlined holes ( $4 \mathrm{~cm}$ diam.) to allow for air circulation. Five male and five female adult $M$. quadrilineatus leafhoppers (which did not carry AY-WB) were introduced into the cage and allowed free access to both leaves. Eggs were dissected and counted under stereomicroscipe $(15 \times) 5$ days after the first day of exposure to the insects.

\section{Statistical Analysis}

Statistical analysis was performed in Minitab16. Insect oviposition data were analyzed using paired $t$-test, twotailed $t$-test or GLM. Assumptions of the statistical tests normal distribution and equal variance - were checked with the Anderson-Darling and the Levene's tests, respectively.

\section{RESULTS}

The aster leafhopper $M$. quadrilineatus is the most important insect vector of the phyllody-inducing ' $\mathrm{Ca}$. Phytoplasma asteris' strain AY-WB (Frost et al., 2011, 2013). This leafhopper favors the colonization of plants with leaf-like flowers (phytoplasmainfected rad23bd mutant plants and GFP-SAP54 transgenic plants) versus plants with wild-type flowers (phytoplasmainfected rad23bcd mutant plants and GFP transgenic plants; MacLean et al., 2014). These results prompted us to further examine if the insects are attracted by leaf-like flowers or repelled by wild-type flowers of phytoplasma-infected $\mathrm{rad} 23 \mathrm{bd} / \mathrm{rad} 23 \mathrm{bcd}$ plants. Interestingly, leafhoppers resided and appeared to feed equally well on wild type and leaf-like floral structures (Figure 1A), suggesting that the insects do not prefer the leaf-like flowers to the wild-type ones. Moreover, we noticed, that most leafhoppers preferred to reside on the rosette leaves rather than floral stems or flowers (Figure 1B), suggesting that the flowers may not be required for leafhopper attraction. Nonetheless, we found that the insects spent more time on GFP-SAP54 transgenic plants with leaf-like flowers versus GFP transgenic plants with wild-type flowers (Figure 2), and these insects produced more progeny on GFP-SAP54 transgenic plants with leaf-like flowers (Figure 3A; Supplementary Figure S1A). However, when insects were not given a choice between host plants, by caging the leafhoppers on either GFP-SAP54 transgenic plants with leaf-like flowers or control GFP transgenic plants with wild type flowers, no increase in nymph production was observed (Figure 4). Thus, the observed leafhopper preference is the result of preferential orientation to plants with leaf-like flowers rather than an increase in reproductive efficiency of the leafhoppers on these plants.

To analyze the impact of leaf-like flowers on leafhopper preference further, we removed both the leaf-like and wildtype flowers from plants in the insect choice experiments and found that the leafhoppers then also preferred the GFP-SAP54 plants (Figure 3B; Supplementary Figure S1A), suggesting that the presence of leaf-like flowers are not required for leafhopper 

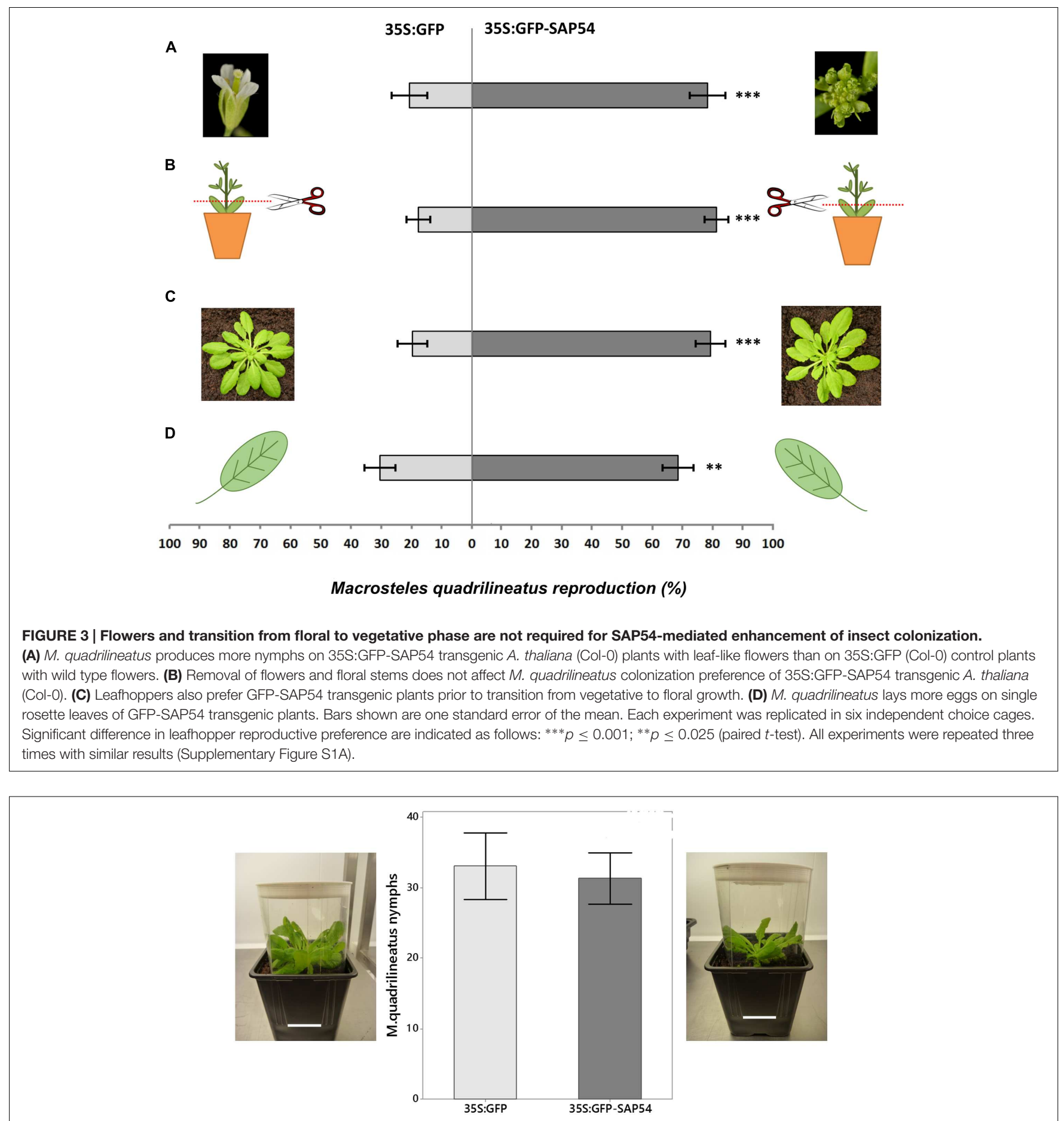

FIGURE 4 | Macrosteles quadrilineatus leafhoppers produced similar nymph numbers when confined to 35S:GFP-SAP54 or 35S:GFP plants (no choice tests). Leafhoppers were released on whole plants, which were caged inside a plastic tube as shown at left and right (picture scale bars are $5 \mathrm{~cm}$ ). The middle graphs show mean numbers of leafhopper nymphs produced in these cages of three independent experiments (paired $t$-test; $n=6 ; p=0.773$ ). Bars shown are one standard error of the mean.

preference of GFP-SAP54 plants. A. thaliana plants used in insect choice tests so far were grown at long days to induce bolting and flowering. Next, we conducted choice tests on A. thaliana plants grown at short days that did not flower. Again, M. quadrilineatus produced more nymphs on GFP-SAP54 versus GFP (control) plants (Figure 3C; Supplementary Figure S1A), suggesting that insect preference for the GFP-SAP54 plants does not involve physiological and developmental transformations during floral 


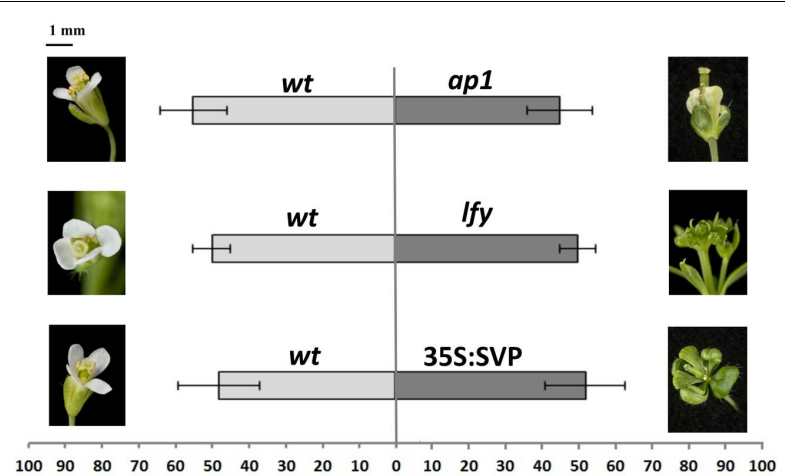

Macrosteles quadrilineatus nymphs (\%)

FIGURE 5 | Aster leafhopper M. quadrilineatus has similar oviposition preference for plants with normal and leaf-like flower phenotype that do not express SAP54. M. quadrilineatus did not show a preference for colonization of Col-0 wild-type versus Col-0 apetala1 (ap1-12; $p=0.835$ ), Col-0 versus Col-0 leafy (Ify- $1 ; p=0.985$ ) and Col-0 versus 35S:SVP (Col-0; $p=0.960)$. Choice experiments were conducted with whole plants retaining both vegetative and floral organs. Data shown as percentage of M. quadrilineatus nymphs found on each test plant per total number of nymphs within a single choice cage (bars are standard error of the mean). Data were analyzed by paired $t$-tests. All experiments were repeated three times with similar results (Supplementary Figure S1B). Picture scale bar is approximately $1 \mathrm{~mm}$.

transition. To confirm this finding, leafhoppers were also given a choice between single leaves of GFP-SAP54 and GFP plants. We found that the leafhoppers preferred to lay eggs onto single leaves of GFP-SAP54 plants (Figure 3D; Supplementary Figure S1A), indicating that leafhoppers are attracted solely to the leaves of GFP-SAP54 plants. Taken together, these data demonstrate that leaf-like flowers are not required for host plant selection by the leafhopper vector, and that SAP54 modulates processes in leaves to promote leafhopper attraction.

The above experiments provide evidence that leaf-like flowers are not required for insect vector preference. Nonetheless, these flowers could contribute to the insect preference. To test this, we conducted choice experiments with $A$. thaliana lines displaying leaf-like flowers, including MTF mutant lines ap1 (Mandel et al., 1992) and lfy (Weigel et al., 1992) and the 35S:SVP transgenic line (Gregis et al., 2013). All these lines produce flowers that share leaf-like structures reminiscent to those of phytoplasmainfected and GFP-SAP54 transgenic plants (MacLean et al., 2011). We found that leafhoppers produce similar numbers of progeny on both plants indicating no colonization preference for plants with leaf-like floral phenotypes (Figure 5; Supplementary Figure $\mathrm{S} 1 \mathrm{~B})$ that is in agreement with our observation that leafhoppers make a choice based on the presence of rosette leaves only (Figure 3D). Thus, the leaf-like flowers are not required for leafhopper preference of GFF-SAP54 plants.

\section{DISCUSSION}

Hitherto, direct analyses of the adaptive significance of parasite extended phenotypes have been limited because many parasites (such as phytoplasma) are not amenable to genetic manipulation and parasite genetic factors that induce the dramatic host alterations are often unknown. Given that leafhoppers feed and lay eggs mostly on vegetative tissues, including stems and leaves, and that the plant $26 \mathrm{~S}$ proteasome cargo protein RAD23 is required for both the induction of leaf-like flowers and insect vector attraction (Weintraub and Beanland, 2006; MacLean et al., 2014), we hypothesized that leafhoppers may be attracted to leaf-like flowers of phytoplasma-infected and SAP54 transgenic plants. However, this study has shown that leaf-like flowers are not required nor are involved in attraction of the phytoplasma insect vectors. Moreover, leafhoppers preferred plant vegetative tissues above reproductive organs. Thus, leaf-like flowers do not promote leafhopper colonization, even though these two phenotypes are genetically connected via SAP54 interaction with the 26S proteasome cargo protein RAD23 (MacLean et al., 2014) (Figure 6).

Phyllody-inducing ' $\mathrm{Ca}$. Phytoplasma asteris' phytoplasmas, such as AY-WB, often infect annual plants (Lee et al., 2004), which die upon flowering and seed production. Phytoplasmas are dependent on insect vectors for spread before plants die (Weintraub and Beanland, 2006). Hence, phytoplasmas that produce effectors, such as SAP54, which attract insect vectors are likely to spread faster than phytoplasmas that do not produce such effectors. Therefore it is likely that insect vector attraction is the extended phenotype of SAP54. Whether leaf-like flowers have a role in promoting phytoplasma fitness has become less clear. It

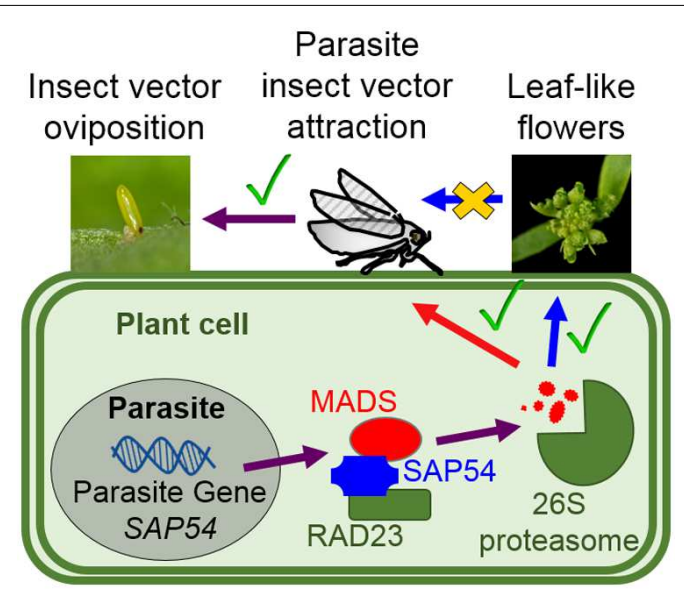

FIGURE 6 | Phytoplasma effector SAP54 mediates insect vector attraction to host plants independently of the presence of leaf-like flowers. The phytoplasma virulence protein (effector) SAP54 interacts with specific MADS-box transcription factors (MTFs) and degrades these via the $26 \mathrm{~S}$ proteasome leading to the development of leaf-like flowers that resemble those of phytoplasma-infected plants (MacLean et al., 2011, 2014). The SAP54-mediated degradation of MTFs is dependent on SAP54 interaction with the 26S proteasome shuttle factor RAD23 (MacLean et al., 2014). Leafhoppers prefer to lay eggs on SAP54 transgenic lines and phytoplasma-infected plants and this preference is also dependent on RAD23 (MacLean et al., 2014). Nonetheless, leaf-like flowers are not required for the leafhopper egg-laying preference. Whether MTFs that are degraded by SAP54 regulate other cellular processes, such as plant defense responses to insect pests, remains to be investigated. 
is possible that the induction of phyllody is a side effect of SAP54mediated modulation of processes involved in insect attraction. SAP54 induces leaf-like flowers by mediating degradation of MTFs via interaction with RAD23 (MacLean et al., 2014). MTFs are regulatory hubs for a plethora of physiological processes in plants, including plant immunity (comparable to animal HOX genes); several MTFs appear to (in)directly regulate cytokinin and JA synthesis and response genes (Gregis et al., 2013), which affect plant-insect interactions (Erb et al., 2012; Giron and Glevarec, 2014; Naessens et al., 2015; Schafer et al., 2015), such as that of the AY-WB leafhopper vector M. quadrilineatus (Sugio et al., 2011a). In addition, MTFs regulate age-related resistance responses to pests (Wilson et al., 2013). Therefore, SAP54mediated degradation of MTFs may modulate plant immunity leading to attraction of the leafhoppers.

Another AY-WB phytoplasma effector, SAP11, binds and destabilizes specific members of the TCP family and promotes leafhopper oviposition activity in no-choice tests (Bai et al., 2012; Sugio et al., 2011a, 2014). TCPs are transcription factors that are conserved among plants and are regulatory hubs for plant growth and organ formation. In addition, TCPs regulate a variety of microRNAs and the plant defense hormones JA (Schommer et al., 2008; Immink et al., 2012) and SA (Wang et al., 2015). Another phytoplasma effector, Tengu, also induces witch's broom-like symptoms in plants (Hoshi et al., 2009) and alters the plant JA and auxin hormone balance (Minato et al., 2014), and it was suggested that the witch's broom-like symptoms attract the leafhopper vectors (Hoshi et al., 2009). However, given that SAP11 decreases JA production, which increases leafhopper colonization (Kallenbach et al., 2012; Lu et al., 2014; Sugio et al., 2011b), it remains to be investigated if witch's broom symptoms are involved in the leafhopper colonization preference. Thus, the SAP54, SAP11, and TENGU effectors all alter plant development that resemble symptoms of phytoplasma-infected plants, but for SAP54 we have now shown that the alterations in plant development (leaf-like flowers) are not required for insect preference.

Targeting conserved plant proteins, such as MTFs and TCPs by phytoplasma effector proteins may enable the phytoplasma parasites to infect a broad range of plant species. The $26 \mathrm{~S}$ proteasome shuttle proteins RAD23 are also conserved among plant species (Vierstra, 2009). Compatibility of phytoplasmas with multiple plant species is likely essential given that AYWB phytoplasma and related parasites are transmitted by polyphagous insect species, such as leafhoppers of the genus Macrosteles (Lee et al., 2004; Weintraub and Beanland, 2006). Because these insects readily feed on many plant species, phytoplasmas will increase their fitness if they can modulate these plants to increase attraction and colonization of insect vectors. In agreement with this, SAP54 homologs are found in diverse phyllody-inducing phytoplasmas that infect a wide range of plant species (Bertaccini, 2007; MacLean et al., 2011; Maejima et al., 2014). Thus, generalist parasites, especially those dependent on alternative hosts for transmission, could gain fitness benefits via interfering with conserved host processes.

It is often argued that phenotypes induced by parasites have a direct positive relationship with parasite fitness (Gould and Lewontin, 1979; Dawkins, 1982, 1990). For example, frogs infected with Ribeiroia trematode species lose their legs and it is thought that this enhances the likelihood of these frogs to be eaten by birds, which are the secondary hosts (or vectors) of the trematodes. Because the trematodes depend on the birds for transmission to frogs (trematode-infested bird excretions get into snails, which are then eaten again by frogs), the trematode-induced alterations of frog morphology is seen as an adaptive parasite-induced phenotype, which has the primary role of enhancing trematode spread. Our hypothesis that leaflike flowers promote insect vector attraction was argued from an adaptionist point of view, which was reinforced by our finding that SAP54 interaction with RAD23 is required for both leaf-like flower formation and insect vector attraction (MacLean et al., 2014). However, an alternative non-adaptionist view is that parasite-induced phenotypes are not always adaptive and could be side effects or secondary phenomena that have neutral effects on (parasite) fitness (Gould and Lewontin, 1979). In agreement with this, our results suggest that the formation of leaf-like flowers may be a phenotype that is secondary or a side effect to the primary role of SAP54 and phytoplasmas to attract leafhoppers (Figure 6). Therefore, leaflike flowers may be an example of a non-adaptive parasiteinduced phenotype.

\section{AUTHOR CONTRIBUTIONS}

ZO designed the experiments, carried out all experimental work, performed data analysis and wrote the manuscript; $\mathrm{SH}$ initiated the project, coordinated the study and wrote the manuscript. All authors give final approval for publication.

\section{FUNDING}

The work was funded by BBSRC (BB/J0045531/1) and a BBSRC student fellowship awarded to ZO.

\section{ACKNOWLEDGMENTS}

We thank Enrico Coen and Sophien Kamoun for critical feedback on manuscript versions, Richard D. Vierstra (Department of Genetics, University of Wisconsin-Madison) and Martin M. Kater (Department of Bioscience, Università degli Studi di Milano) for kindly providing seed of $A$. thaliana rad23 mutants and 35S:SVP overexpression lines, respectively. We are grateful to Ian Bedford, Anna Jordan, and Gavin Hatt (JIC Insectary) for rearing and care of leafhopper and phytoplasma stocks and the John Innes Horticultural Services for growing the plants used in this study. We also thank Andrew Davis for plant photographs.

\section{SUPPLEMENTARY MATERIAL}

The Supplementary Material for this article can be found online at: http://journal.frontiersin.org/article/10.3389/fpls.2016.00885 


\section{REFERENCES}

Artero, R., Furlong, E. E., Beckett, K., Scott, M. P., and Baylies, M. (2003). Notch and Ras signaling pathway effector genes expressed in fusion competent and founder cells during Drosophila myogenesis. Development 130, 6257-6272. doi: 10.1242/dev.00843

Bai, F., Reinheimer, R., Durantini, D., Kellogg, E. A., and Schmidt, R. J. (2012). TCP transcription factor, BRANCH ANGLE DEFECTIVE 1 (BAD1), is required for normal tassel branch angle formation in maize. Proc. Natl. Acad. Sci. U.S.A. 109, 12225-12230. doi: 10.1073/pnas. 1202439109

Berdoy, M., Webster, J. P., and Macdonald, D. W. (2000). Fatal attraction in rats infected with Toxoplasma gondii. Proc. R. Soc. B-Biol. Sci. 267, 1591-1594. doi: 10.1098/rspb.2000.1182

Bertaccini, A. (2007). Phytoplasmas: diversity, taxonomy, and epidemiology. Front. Biosci. 12:673-689. doi: 10.2741/2092

Cezilly, F., Favrat, A., and Perrot-Minnot, M. J. (2013). Multidimensionality in parasite-induced phenotypic alterations: ultimate versus proximate aspects. J. Exp. Biol. 216, 27-35. doi: 10.1242/jeb.074005

Dawkins, R. (1982). The Extended Phenotype: The Long Reach of the Gene. Oxford: Oxford University Press.

Dawkins, R. (1990). Parasites, desiderata lists and the paradox of the organism. Parasitology 100, S63-S73. doi: 10.1017/S0031182000073029

Dawkins, R. (2004). Extended phenotype - But not too extended. A reply to Laland, Turner and Jablonka. Biol. Philos. 19, 377-396. doi: 10.1023/B:BIPH.0000036180.14904.96

Erb, M., Meldau, S., and Howe, G. A. (2012). Role of phytohormones in insect-specific plant reactions. Trends Plant Sci. 17, 250-259. doi: 10.1016/j.tplants.2012.01.003

Frost, K. E., Esker, P. D., Van Haren, R., Kotolski, L., and Groves, R. L. (2013). Factors influencing aster leafhopper (Hemiptera: Cicadellidae) abundance and aster yellows phytoplasma infectivity in Wisconsin carrot fields. Environ. Entomol. 42, 477-490. doi: 10.1603/EN12239

Frost, K. E., Willis, D. K., and Groves, R. L. (2011). Detection and variability of aster yellows phytoplasma titer in its insect vector, Macrosteles quadrilineatus (Hemiptera: Cicadellidae). J. Econ. Entomol. 104, 1800-1815. doi: 10.1603/EC11183

Giron, D., and Glevarec, G. (2014). Cytokinin-induced phenotypes in plant-insect interactions: learning from the bacterial world. J. Chem. Ecol. 40, 826-835. doi: 10.1007/s10886-014-0466-5

Gould, S. J., and Lewontin, R. C. (1979). Spandrels of san-marco and the panglossian paradigm - a critique of the adaptationist program. Proc. R. Soc. Ser. B Biol. Sci. 205, 581-598. doi: 10.1098/rspb.1979.0086

Gregis, V., Andres, F., Sessa, A., Guerra, R. F., Simonini, S., Mateos, J. L., et al. (2013). Identification of pathways directly regulated by SHORT VEGETATIVE PHASE during vegetative and reproductive development in Arabidopsis. Genome Biol. 14:R56. doi: 10.1186/gb-2013-14-6-r56

Hoover, K., Grove, M., Gardner, M., Hughes, D. P., McNeil, J., and Slavicek, J. (2011). A gene for an extended phenotype. Science 333, 1401-1401. doi: 10.1126/science. 1209199

Hoshi, A., Oshima, K., Kakizawa, S., Ishii, Y., Ozeki, J., Hashimoto, M., et al. (2009). A unique virulence factor for proliferation and dwarfism in plants identified from a phytopathogenic bacterium. Proc. Natl. Acad. Sci. U.S.A. 106, 6416-6421. doi: 10.1073/pnas.0813038106

Immink, R. G. H., Pose, D., Ferrario, S., Ott, F., Kaufmann, K., Valentim, F. L., et al. (2012). Characterization of SOC1's central role in flowering by the identification of its upstream and downstream regulators. Plant Physiol. 160, 433-449. doi: 10.1104/pp.112.202614

Johnson, P. T. J., Sutherland, D. R., Kinsella, J. M., and Lunde, K. B. (2004). Review of the trematode genus Ribeiroia (Psilostomidae): ecology, life history and pathogenesis with special emphasis on the amphibian malformation problem. Adv. Parasitol. 57, 191-253. doi: 10.1016/S0065-308X(04) 57003-3

Kallenbach, M., Bonaventure, G., Gilardoni, P. A., Wissgott, A., and Baldwin, I. T. (2012). Empoasca leafhoppers attack wild tobacco plants in a jasmonatedependent manner and identify jasmonate mutants in natural populations. Proc. Natl. Acad. Sci. U.S.A. 109, E1548-E1557. doi: 10.1073/pnas.12003 63109
Lee, I. M., Gundersen-Rindal, D. E., Davis, R. E., Bottner, K. D., Marcone, C., and Seemuller, E. (2004). 'Candidatus Phytoplasma asteris', a novel phytoplasma taxon associated with aster yellows and related diseases. Int. J. Syst. Evol. Microbiol. 54, 1037-1048. doi: 10.1099/ijs.0.02843-0

Lemaitre, B., Nicolas, E., Michaut, L., Reichhart, J. M., and Hoffmann, J. A. (1996). The dorsoventral regulatory gene cassette spatzle/Toll/cactus controls the potent antifungal response in Drosophila adults. Cell 86, 973-983. doi: 10.1016/S0092-8674(00)80172-5

Lu, Y. T., Li, M. Y., Cheng, K. T., Tan, C. M., Su, L. W., Lin, W. Y., et al. (2014). Transgenic plants that express the phytoplasma effector SAP11 show altered phosphate starvation and defense responses. Plant Physiol. 164, 1456-1469. doi: 10.1104/pp.113.229740

MacLean, A. M., Orlovskis, Z., Kowitwanich, K., Zdziarska, A. M., Angenent, G. C., Immink, R. G. H., et al. (2014). Phytoplasma effector SAP54 hijacks plant reproduction by degrading MADS-box proteins and promotes insect colonization in a RAD23-dependent manner. PLoS Biol. 12:e1001835. doi: 10.1371/journal.pbio.1001835

MacLean, A. M., Sugio, A., Makarova, O. V., Findlay, K. C., Grieve, V. M., Toth, R., et al. (2011). Phytoplasma effector SAP54 induces indeterminate leaflike flower development in Arabidopsis plants. Plant Physiol. 157, 831-841. doi: 10.1104/pp.111.181586

Maejima, K., Iwai, R., Himeno, M., Komatsu, K., Kitazawa, Y., Fujita, N., et al. (2014). Recognition of floral homeotic MADS domain transcription factors by a phytoplasmal effector, phyllogen, induces phyllody. Plant J. 78, 541-554. doi: $10.1111 /$ tpj.12495

Mandel, M. A., Gustafson-Brown, C., Savidge, B., and Yanofsky, M. F. (1992). Molecular characterization of the Arabidopsis floral homeotic gene APETALA1. Nature 360, 273-277. doi: 10.1038/360273a0

Minato, N., Himeno, M., Hoshi, A., Maejima, K., Komatsu, K., Takebayashi, Y., et al. (2014). The phytoplasmal virulence factor TENGU causes plant sterility by downregulating of the jasmonic acid and auxin pathways. Sci. Rep. 4:7399. doi: $10.1038 /$ srep07399

Naessens, E., Dubreuil, G., Giordanengo, P., Baron, O. L., Minet-Kebdani, N., Keller, H., et al. (2015). A secreted MIF cytokine enables aphid feeding and represses plant immune responses. Curr. Biol. 25, 1898-1903. doi: 10.1016/j.cub.2015.05.047

Poulin, R. (1995). "Adaptive" changes in the behaviour of parasitized animals: a critical review. Int. J. Parasitol. 25, 1371-1383. doi: 10.1016/00207519(95)00100-X

Poulin, R. (2013). Parasite manipulation of host personality and behavioural syndromes. J. Exp. Biol. 216, 18-26. doi: 10.1242/jeb.073353

Schafer, M., Meza-Canales, I. D., Navarro-Quezada, A., Brutting, C., Vankova, R., Baldwin, I. T., et al. (2015). Cytokinin levels and signaling respond to wounding and the perception of herbivore elicitors in Nicotiana attenuata. J. Integr. Plant Biol. 57, 198-212. doi: 10.1111/jipb.12227

Schommer, C., Palatnik, J. F., Aggarwal, P., Chetelat, A., Cubas, P., Farmer, E. E., et al. (2008). Control of jasmonate biosynthesis and senescence by miR319 targets. PLoS Biol. 6:e230. doi: 10.1371/journal.pbio.0060230

Sugio, A., Kingdom, H. N., MacLean, A. M., Grieve, V. M., and Hogenhout, S. A. (2011a). Phytoplasma protein effector SAP11 enhances insect vector reproduction by manipulating plant development and defense hormone biosynthesis. Proc. Natl. Acad. Sci. U.S.A. 108, E1254-E1263. doi: 10.1073/pnas.1105664108

Sugio, A., MacLean, A. M., Kingdom, H. N., Grieve, V. M., Manimekalai, R., and Hogenhout, S. A. (2011b). Diverse targets of Phytoplasma effectors: from plant development to defense against insects. Annu. Rev. Phytopathol. 49, 175-195. doi: 10.1146/annurev-phyto-072910-095323

Sugio, A., MacLean, A. M., and Hogenhout, S. A. (2014). The small phytoplasma virulence effector SAP11 contains distinct domains required for nuclear targeting and CIN-TCP binding and destabilization. New Phytol. 202, 838-848. doi: $10.1111 / \mathrm{nph} .12721$

Vierstra, R. D. (2009). The ubiquitin-26S proteasome system at the nexus of plant biology. Nat. Rev. Mol. Cell Biol. 10, 385-397. doi: 10.1038/nrm2688

Wang, X., Gao, J., Zhu, Z., Dong, X., Wang, X., Ren, G., et al. (2015). TCP transcription factors are critical for the coordinated regulation of ISOCHORISMATE SYNTHASE 1 expression in Arabidopsis thaliana. Plant J. 82, 151-162. doi: 10.1111/tpj.12803 
Weigel, D., Alvarez, J., Smyth, D. R., Yanofsky, M. F., and Meyerowitz, E. M. (1992). LEAFY controls floral meristem identity in Arabidopsis. Cell 69, 843-859. doi: 10.1016/0092-8674(92)90295-N

Weintraub, P. G., and Beanland, L. (2006). Insect vectors of phytoplasmas. Annu. Rev. Entomol. 51, 91-111. doi: 10.1146/annurev.ento.51.110104.151039

Wilson, D. C., Carella, P., Isaacs, M., and Cameron, R. K. (2013). The floral transition is not the developmental switch that confers competence for the Arabidopsis age-related resistance response to Pseudomonas syringae pv. tomato. Plant Mol. Biol. 83, 235-246. doi: 10.1007/s11103-013-0 083-7
Conflict of Interest Statement: The authors declare that the research was conducted in the absence of any commercial or financial relationships that could be construed as a potential conflict of interest.

Copyright $\odot 2016$ Orlovskis and Hogenhout. This is an open-access article distributed under the terms of the Creative Commons Attribution License (CC BY). The use, distribution or reproduction in other forums is permitted, provided the original author(s) or licensor are credited and that the original publication in this journal is cited, in accordance with accepted academic practice. No use, distribution or reproduction is permitted which does not comply with these terms. 